\title{
Un prodigio literario
}
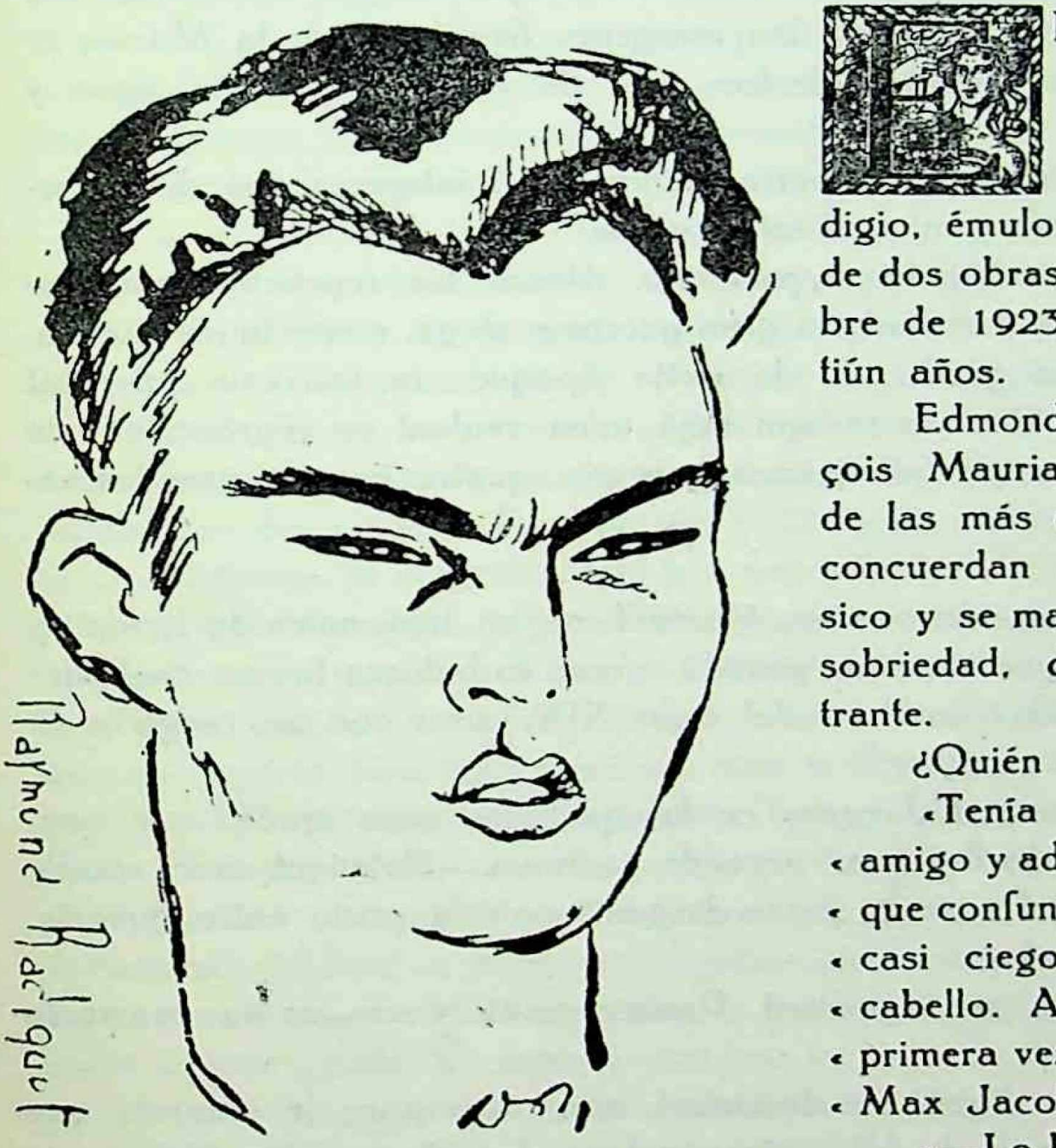

$\mathrm{N}$ todos los números de las últimas revistas francesas vienen articulos sobre Raymond Radiguet, el niño prodigio, émulo de Rimbaud en prosa, autor de dos obras maestras, muerto en Diciembre de 1923. antes de cumplir los veintiún años.

Edmond Jaloux, Henri Massis, François Mauriac. Jean Cocteau, escritores de las más diversas edades y tendencias concuerdan en darle el epiteto de clásico y se maravillan de su lucidez, de su sobriedad, de su fuerza dura y penetrante.

¿Quién era?

-Tenia 15 años-dice Cocteau. su - amigo y admirador-y se atribuía 18: lo - que confunde a los biógralos. Era miope. - casi ciego. No se cortaba nunca el - cabello. Abría rara vez la boca. La - primera vez que me visitó. enviado por - Max Jacob. me dijeron:

- Lo busca un niño con bastón.

-Habitaba el parque de Saint Maur, al borde de la Marne, y lo llamába- mos el milagro de la Marne. Rara vez volvia a su casa y dormia en cualquier - parte, en el suelo, en una mesa, en casa de los pintores de Montparnasse o - Montmartre. A veces sacaba del bolsillo un pedazo de papel arrugado y su- cio. Lo desenvolvía con cuidado y leiamos un poema fresco como una concha

- marina, como un racimo de grosellas,

-Le Diable $A u$ Corps,, su primera novela, refleja un poco ese ambiente. Un 
muchacho de 16 años, que cumplió doce al empezar la guerra, cuenta sus amores con una joven de 19 , recién casada. cuyo marido parte a las trincheras a los quince días de matrimonio. Son amores enteramente libres, de un paganismo fresco, evocador del idilio de Longus. Se aman, se entregan, se poseen y no hay otros conflictos que los muy menudos de las entrevistas cada vez menos furtivas. La primera vez que él deja su casa para alojar en la de ella. inventa una excursión de madrugada con un amigo y la madre le prepara un cesto de provisiones que lo pone en duros aprietos. Después las relaciones siguen con la tolerancia familiar. Una mañana sale él de casa de su Julieta, descalzo, con los zapatos en la mano y encuentra al lechero que llega: sll tenait ses boites de lait a la main; je tenais, moi, mes souliers. Il me souhaita le bonjour avec un sourire terrible. Marthe était perdue. Il allait le raconter... Lo cuenta, mas no por eso Marta se considera perdida. Salen a excursionar juntos por las orillas del río, se embarcan y bogan en paz entre las márgenes frondosas de la Marne, se dejan mecer sin temores, sin remordimientos, por la voluptuosidad del agua y del amor.

Todos los incidentes son de este porte, minimos; el interés surge de la forma lapidaria y de la agudeza con que están vistos.

Sólo hay un pequeño escrúpulo al principio. Prevé los reproches que merecerá su actitud poco heroica durante la gran guerra y alega, como única excusa, su edad: .Et mes camarades garderont de cette époque un souvenir qui n'est - pas celui de leurs aînés. Que ceux qui déjà m en veulent se répresentent ce - que lut la guerre pour tant de très jeunes garçons: quatre ans de grandes va- cancess.

\section{|Bonitas vacaciones!}

La guerra termina, el marido vuelve. Marta tiene un hijo antes de tiempo y muere. Y la obra concluye, no con un gemido, como lo hubiera hecho cualquier adolescente o cualquier hombre maduro del siglo XIX, sino con un rasgo a lo Voltaire, puro siglo XVIII:

.La seule fois que $\mathrm{j}$ 'aperçus Jacques ce fut quelques mois après... Je vou- lus voir l'homme auquel Marthe avait accordé sa main.-Retenant mon souffle - et marchant sur la pointe des pieds, je me dirigeais vers la porte entre ouverte. - J'arrivais juste pour entendre:

- Ma femme est morte en l'appelant. Pauvre petitl N'est-ce pas ma seule - raison de vivre?

-En voyant ce veuf si digne et dominant son désespoir, je compris que - l'ordre, à la longue, se met de lui-même autour des choses. Ne venais-je - pas d'apprendre que Marthe était morte en m'appelant (el niño recibió el nom- bre del amante, su padre verdadero) et que mon fils aurait une existence rai- sonnable?,

Respondiendo a las críticas que se hicieron del libro. Cocteau afirma que Raymond Radiguet no tenía el corazón seco, sino duro, de diamante, y que para reaccionar necesitaba el contacto del fuego o de otros diamantes. Desdeñaba el 
resto. En realidad, la moral, el cristianismo, los escrúpulos sociales pasaron por su espiritu, en ese libro, ccomo sobre el cristal la sombra pasa.

$\mathrm{Y}$ júzguesele desde uno u otro punto de vista, creemos que éste constituye el primer prodigio de su temperamento. Una amoralidad serena y total, un cinismo que llega a parecer inocente, la falta absoluta de todo formento de conciencia. Lejos la magnifica melancolía de René. la apasionada inquietud de Roland todo el infinito romántico. La realidad precisa envuelta, como el músculo en la piel, en una frase desnuda y flexible.

El autor se defendió, en una nota suelta, del cargo de haberse confesado. otra mania de 1830: .On a voulu voir en mon livre des confessiones. Quelle erreur! Les - prêtres connaissent bien ce mécanisme de l'ame, observé chez les jeunes garçons - et chez les femmes, de fausses confessions, celles oû l'on se charge de méfaits non - commis, par orgueil. C est à la fois pour donner au Diable le relief d'un roman - que tout y est faux, et ensuite pour peindre la psychologie du jeune garçon, héros - du livre. Cette fanfaronnade fait partie de son caractère. Nos cuesta creerlo. De todas maneras, un conocimiento tan exacto, tan próximo, equivale a la acción. Y acaso tiene mayor gravedad por la clarividencia.

La otra novela se bal du Comte d'Orgels queda, moralmente, en el extremo opuesto. Radiguet la definió en dos frases profundas que bastarían explicar para analizarla: .Novela de un amor casto, tan escabrosa como la novela menos casta... Novela en que la psicología (y solamente la psicología, añadiriamos) es novelescas.

Novela de un amor casto... La Condesa de Orgel, perteneciente a una familia ilustre, ama a su marido, no ve ningún otro hombre sobre la tierra. Entre sus visitantes, hay dos jóvenes. Paul Robin y François de Séryeuse, naturalezas profundamente distintas. El segundo es el que nos interesa. Es un excelente muchacho, buen hijo, carácter tranquilo, algo solitario. Lentamente, sin advertirlo casi, se enamora de la Condesa, que es muy bella. La Condesa, absorta en su amor conyugal, no se defiende y al cabo se encuentra, como quien abre de pronto los ojos junto a un abismo, con que no ama a su marido y ama a François de Séryeuse. No sucede nada. en el sentido dramático de los hechos; todo pasa adentro. $\mathrm{Y}$ sin embargo, el relato apasiona como la más movida novela de aventuras y no hay una página que no avance el proceso sentimental, que no abra una nueva perspectiva y mantenga tirante la curiosidad. Al final se producen algunos incidentes de intriga. La Condesa, espantada de su amor, queriendo defenderse, acude a la madre del joven. le confiesa el peligro, le pide ayuda. La señora, con una torpeza de mujer buena, le dice en una entrevista que François está enamorado de ella. Y por el rostro de la mujer impecable pasa divina, incontenible alegría. ¡La ama! Es un relámpago. Pero el resplandor le cegará los ojos. La señora, desconcertada, vuelve a su casa. encuentra a su hijo. le da la carta de la Condesa. Y asi se produce la declaración intima que ninguno se atrevía a formular. Durante un baile en casa de los Condes de Orgel. la Condesa se desmaya de impresión ante François, a quien sabe poseedor de su secreto, y como último recurso, semejante a la Princesa de Cléves, se lo cuenta todo al Conde. El Conde no entiende nada. Quiere mucho a François. Rehusa darle importancia a la cosa. Es un hombre de mundo, de gran mundo, y esos asuntos lo fastidian. En rea- 
lidad, no quiere a su mujer. Ella lo comprende y la última barrera de su virtud cae. Es el final. No ha pasado nada y ha sucedido todo...

Examinando la situación de Raymond Radiguet en la Historia, se ha discutido si pertenece a nuestra época y si revela influencia de Marcel Proust.

Las dos conclusiones a que llegan M. Bernard Fay y M. Edmond Jaloux nos parecen equivocadas.

Sostiene el primero que Radiguet no tiene nada que hacer con nuestra época ni con ninguna otra, que es uno de esos hombres felizmente dotados a quienes no alcanza la influencia del ambiente. Su .Bal du Comte d'Orgel, sería un anillo más de la cadena que empieza en La Princesa de Cléves. obra maestra aparte, un tanto milagrosa.

El segundo afirma que Proust no puede reivindicar la paternidad del joven novelista, cuyo análisis se mueve siempre en esas regiones moderadas que baña la claridad de la conciencia, mientras el caminante de Swan investiga más lejos, tierras misteriosas.

Raymond Radiguet no pertenece al siglo XIX. Es evidente. Jamás describe la naturaleza, ignora el paisaje, apenas esboza la figura física de sus héroes; su prosa nítida, de frase corta, incisiva, sagaz, recuerda mejor a los escritores del siglo XVIII y lo emparenta con Voltaire. Tiene el sarcasmo más envuelto y como encarnado en el relato mismo; exteriormente, se le parece mucho. Pero en la sutileza de las imágenes y en lo inesperado de algunas asociaciones de ideas se siente al escritor que pasó por el simbolismo y el modernismo. logrando salir claro de esas turbias aguas. La misma evolución de Duhamel. Romains y tantos contemporáneos exquisitos.

El procedimiento psicológico, el nervio. la sintesis, lo vital de su arte, nos parecen proceder directamente de Marcel Proust. Es un Marcel Proust más concentrado. más sencillo; pero con la misma formidable penetración y ese arte de los detalles esenciales, vastamente interpretados, que hacen tan extraño y tan seductor al analista del Tiempo Perdido.

Por más que él y sus amigos se empeñen en negarlo. Tué un niño prodigio, una especie de fenómeno, casi un monstruo. ¿Es el primero, en realidad, que nos revela el modo de sentir y de pensar de la adolescencia? Estariamos por negarlo. No encontramos en Radiguet nada de lo que caracteriza esa edad dolorosa. Sería necesario reformar por completo el concepto que tenemos de semejante periodo. no sólo de acuerdo con las lecturas, sino con nuestros propios recuerdos, para admitir que ésa sea la verdadera adolescencia. Tanta firmeza, tanta claridad, ese mirar tranquilo y desnudo. sobre todo, esa mesura inflexible y apretada no se encuentran en la juventud normal. Radiguet no fué joven, no tuvo quince ni veinte años: tuvo cuarenta. cincuenta, ciento. Lo sabía todo. porque sabía lo más difícil, que es el corazón humano. Y lo sabia minuciosamente, en sus repliegues recónditos, en sus pequeños e imperceptibles impulsos. Y lo decía sin aire de descubrir, como el cirujano que da su enseñanza abriendo un cadáver. 
En este sentido y considerando su edad real lo creemos fuera del tiempo y hasta del espacio: literaria, artística, psicológicamente, nos parece un hijo de Proust y no nos causaría asombro si, más tarde, se dijera que habia sido una simple mistificación, que Le Bal du Comte d'Orgel, (no Le Diable Au Corps), se había encontrado en realidad entre los papeles póstumos del autor de Le Côté de Guermantes.

De todas maneras, entre las novelas francesas últimas, estas dos se levantan con sello inconfundible.

Antes de leer los dos volúmenes de Radiguet, me impuse con detenimiento de cuatro o cinco críticas que los analizaban minuciosamente. Después de leerlos, adverti que esas críticas, aunque de notables autores, no me habian dado la menor idea de Radiguet. Parecia que se refirieran a otro. iTemo que con mis impresiones suceda lo mismo! Y quiero añadir, a los párralos ya citados, que dejo en francés para no deformarlos, algunos trozos vertidos al castellano. Al hacerlo, observo que no cuesta mucho con la primera novela; con la segunda resulta casi imposible. Está sembrada de rasgos interesantísimos, pero no se podrian desprender sin que perdieran todo mérito. El relato es de una pieza. Por lo demás, la única manera de conocer una obra ha sido. es y será leerla entera. Los estudios más sinceros y mejor intencionados, las más fieles descripciones. sólo pueden tomarse como una indicación muy vaga, un consejo para leer o no leer.

\section{DE .LE DIABLE DU CORPS,}

El 14 de Julio de 1914, yendo a juntarme con mis hermanos. me sorprendió una muchedumbre agrupada junto a la reja de los Maréchaud. Algunos tilos ocultaban mal la villa, al fondo del jardin. Desde hacia dos horas, una sirviente se habia vuelto loca y, refugiada en el techo, rehusaba descender. Los Maréchaud, espantados por el escándalo, habían cerrado las ventanas, y la tragedia de la loca sobre la techumbre parecia más terrible en aquella casa abandonada. Algunos gritaban. indignados de que los dueños nada hicieran por salvar a la infeliz. Ella vacilaba al andar entre las tejas, sin presentar por otra parte el aspecto de una borracha. Yo hubiera querido permanecer ahi, pero la criada de casa nos llevó. Partí con la muerte en el corazón, rogando a Dios que la mujer estuviera aun sobre el techo cuando volviéramos a buscar a mi padre.

Estaba, en efecto. La concurrencia había disminuido mucho. Por lo demás. para la loca, se trataba sólo de un ensayo más o menos público. Debia estrenarse en la noche, según la costumbre, entre las girándolas luminosas que le formarian escenario. Se encendieron las de la avenida y las del jardín, porque los Maréchaud. a pesar de su fingida ausencia, no se atrevieron a prescindir de la luminarias que les correspondian como personajes notables. Al aspecto fantástico de esa casa del crimen, sobre cuyo techo se paseaba, como sobre el puente de un navio empa- 
vesado, una mujer de cabellos sueltos, contribuía mucho la voz de esa mujer: inhumana, gutural, de una dulzura espeluznante.

Los bomberos de la pequeña comuna, en calidad de cvoluntarioss, se ocupan durante el dia en cualquier cosa menos en las bombas. El lechero, el pastelero, el carpintero llegan a extinguir el incendio, una vez terminado su trabajo, si acaso el incendio no se ha apagado solo. Desde la movilización, los bomberos formaron. además, una especie de milicia misteriosa, que maniobraba en patrullas nocturnas. Estos valientes llegaron al fin y atravesaron la multitud.

Una mujer avanzó. Era la esposa de un municipal adverso a Maréchaud y que desde hacía rato compadecía ruidosamente a la loca. Dirigió recomendaciones al Capitán: Trate de cogerla con dulzura: le hace tanta falta, a la pobre, en esa casa en que la maltratan. Sobre todo, si se teme que la despidan, dígale que yo la tomaré y que le doblaré el sueldo.

Esta caridad ostentosa produjo mediocre efecto en el auditorio. La dama estorbaba. No pensaba sino en la captura. Seis bomberos escalaron la reja, sitiaron la casa, treparon por todos lados. Pero no bien uno de ellos apareció arriba. la muchedumbre, como los niños en el Guignol, se lanzó a vocilerar, a avisar a la víctima.

- iCállensel_gritaba la señora.

Alarmada por las voces, la loca se armó de tejas y lanzó una al casco de un bombero. Los demás bajaron apresuradamente.

Mientras los circos se lamentaban de su poca clientela en esa noche de celebraciones patrióticas. los pilletes escalaban los muros y los árboles para seguir la emocionante caza. La loca decía cosas que he olvidado. con esa prolunda melancolia resignada que da la certidumbre de tener la razón, de que todo el mundo está equivocado. Los niños, que preferían ese espectáculo a toda diversión, querian sin embargo combinar sus placeres y corrian a dar una vuelta de carroussel, temblando de que cogieran a la loca en su ausencia.

Se comprende la angustia de los Maréchaud encerrados en medio de esa bulla y esas luces.

El municipal esposo de la dama caritativa, trepado en la reja, improvisaba un discurso sobre la cobardia de los propietarios, en medio de aplausos y risas.

Creyendo que la aplaudían a ella. la loca saludaba. con una teja en cada mano. lista para arrojarla a la cabeza de los bomberos. Con su voz inhumana, agradecia que al fin la hubieran comprendido. Yo pensaba en alguna amazona de corsarios, que hubiera quedado sola en un navío náufrago.

...Prolongando excesivamente, el espectáculo acabó por fatigar a la concurrencia.

De pronto, sonaron clarines, cien antorchas iluminaron a la loca y ella, agitando los brazos en signo de adiós. convencida de que había llegado el fin del mundo. o simplemente, de que ya la cogian, se lanzó del techo, quebró los cristales de la marquesina y con un estrépito espantoso cayó sobre las piedras de la escalera. Cuando oí decir: .Vive aun», me desmayé en brazos de mi padre. 
...Muchas veces nos tomaron por hermano y hermana. $Y$ es que existen en nosotros gérmenes de semejanza que el amor desarrolla. Un gesto, una inflexión de la voz, tarde o temprano traicionan a los amantes más cautelosos.

Es preciso admitir que si el corazón tiene sus razones que la razón ignora, se debe a que ésta es menos razonable que nuestro corazón. Sin duda, somos todos Narcisos que amamos y aborrecemos nuestra imagen, pero a quienes toda otra imagen resulta indiferente. El instinto de semejanza nos lleva por la vida y nos hace gritar laltol en presencia de un paisaje, de una mujer, de un poema. Podemos admirar otros sin sentir ese choque. El instinto de semejanza es la única línea de conducta que no sea artificial.

En resumen, estaba contento de haber trabado conocimiento, por algunos instantes, con el dolor. Por lo menos, así lo creía. Pero nada se parece menos a las cosas mismas que lo que está muy cerca de ellas. El hombre que casi ha muerto cree conocer la muerte. Cuando ella se presenta al fin, no la reconoce.

- INo es ella!_dice. Y muere.

Los verdaderos presentimientos se forman en profundidades que nuestro espíritu no alcanza. Así a veces nos hacen realizar actos que interpretamos al revés.... El hombre desordenado que va a morir y no lo sospecha, lo ordena todo en su rededor. Su vida cambia. Arregla sus papeles. Se levanta temprano, se acuesta a sus horas. Renuncia a los vicios. Sus amigos lo felicitan. Así su muerte brutal parece más injusta. Iba a vivir dichoso. (El caso exacto del autor. según Rocteau).

\section{DEL BAILE DEL CONDE DE ORGEL}

En Paris, Mirza (principe persa de moda) aparecia frivolo. Se le atribuía el sentido del placer. La razón era simple: si un sitio era melancólico. Mirza se apartaba de su camino. Cazador infatigable, no se obstinaba jamás; y su encarnizamiento en la persecución del placer, de la dicha, probaban sin vuelta que no los poseía.

François de Séryeuse sentía el cansancio modelarle el rostro. Hester (una norte-americana escultora galante) fruncia los ojos como los artistas:

-Ud. tiene mucho más carácter así. Esculpiré su busto cuando esté fatigado. 
¿Pensaba entonces hacer sus sesiones de -pose, después de otras sesiones? François de Séryeuse interpretó inocentemente la frase ni un segundo se le ocurrió que Mrs. Wayne dispusiera, para latigarlo, de otros medios que su conversación. Olvidaba que la norte-americana era mujer y muy hermosa.

Mahaut sacó el espejo que consultaba, no por coquetería, sino como un reloj. para saber si era hora de partir. Sin duda decifró una hora tardía en su rostro, porque se levantó....

Verdaderamente sorprendido, el Conde de Orgel se callaba: porque no tenía talento sino para expresar lo que no sentia. Pasada esa sorpresa, la fingió.

Mme. d'Orgel no se alarmaba de esas largas visitas mudas. Se decia:- Junto a él no siento nada. - ¿No es la perfecta definición de la dicha? La felicidad. como la salud, no se advierten.

- Tengo que hablar con $M$. d'Orgel.

Paul Robin cultivaba ese pudor absurdo, esencialmente moderno, que consiste en no querer parecer engañado por ciertas palabras serias y ciertas fórmulas de respeto. Para no asumir su responsabilidad. las pronuncian como entre comillas.

Así Paul no usaba nunca un lugar común sin precederlo de una pequeña risa o de una aspiración. Quería probar con eso que no era crédulo.

No ser engañado era la enfermedad de Paul Robin. Es la enfermedad del siglo. Puede conducir a veces hasta engañar a los otros.

Todo órgano se atrofia o desarrolla en razón de su actividad. A fuerza de desconfiar del corazón, casi no lo poseía. Creía endurecerse y abroquelarse y se destruía. Completamente equivocado, este suicidio lento era lo que más le gustaba en él. Creía que asi viviria mejor. Pero nadie ha encontrado sino un medio de impedir los latidos del corazón: es la muerte.

La internacional está firmada hace tiempo, mas no donde se cree. Eran pri- 
mos de Paris, de Francia. los que recibian. ¿Por qué los señores participarian en una querella de criados? Los Orgel de Austria juzgaban asi la guerra.

A la distancia cuesta reconocer a las personas, porque son más sinceras. La separación crea barreras materiales; pero suprime otra más importantes. Por carta, los amantes se dicen a veces lo que jamás se hubieran confesado de palabra, lo que ni ellos mismos talvez sospechaban o querían decir. Mme. d'Orgel no se vigilaba en sus cartas. Lo creía innecesario...... Y ellas hacian feliz al joven.

ALONE. 